\title{
Jörn Leonhard, Die Büchse der Pandora. Geschichte des Ersten Weltkriegs
}

München : C. H. Beck, 2014, 1168 p., $38 €$

\section{Bérénice Zunino}

\section{CpenEdition}

\section{Journals}

Édition électronique

URL : http://journals.openedition.org/ifha/8417

DOI : 10.4000/ifha.8417

ISSN : 2198-8943

Éditeur

IFRA - Institut franco-allemand (sciences historiques et sociales)

Référence électronique

Bérénice Zunino, « Jörn Leonhard, Die Büchse der Pandora. Geschichte des Ersten Weltkriegs », Revue de I'IFHA [En ligne], Date de recension, mis en ligne le 01 février 2016, consulté le 22 septembre 2020. URL : http://journals.openedition.org/ifha/8417 ; DOI : https://doi.org/10.4000/ifha.8417

Ce document a été généré automatiquement le 22 septembre 2020

(CIFHA 


\section{Jörn Leonhard, Die Büchse der Pandora. Geschichte des Ersten Weltkriegs}

München : C. H. Beck, 2014, 1168 p., $38 €$

\section{Bérénice Zunino}

La boîte de Pandore de Jörn Leonhard est sans doute l'un des livres qui a retenu le plus l'attention durant le centenaire de 1914. Structurée chronologiquement, cette étude prend en compte les différentes facettes du conflit, militaire, stratégique, économique, politique, sociétale et intellectuelle. Chaque chapitre, dont les différentes sous-parties peuvent être lues comme des essais autonomes, est consacré à une année de guerre. Dans une perspective comparative européenne, J. Leonhard adopte le point de vue des différents pays belligérants sans négliger l'histoire locale et globale du conflit.

Le titre de l'ouvrage illustre d'emblée la thèse défendue : le premier conflit mondial, par la violence qu'il déploya, fut la "guerre qui marqua le tournant d'une époque " (Krieg zur Epochenwende, p. 11). Il fait par ailleurs référence, comme l'explique l'auteur en introduction (p. 9-10), à la pièce que les enfants de Thomas Mann ne purent jouer le $1^{\text {er }}$ août 1914 en raison de la déclaration de guerre allemande à la Russie. J. Leonhard dresse cependant un tableau nuancé de la « catastrophe originelle du XXe siècle» (G. Kennan). D'après l'auteur, le conflit ne marqua pas nécessairement la naissance de la Modernité : s'il bouleversa la pensée politique, économique et philosophique héritée du XIXe siècle (organisation de l'État-nation, ordre économique, positivisme, etc.) et favorisa la radicalisation des idéologies, il resta aussi ancré dans le siècle précédent. En témoignent l'utilisation de chevaux et de pigeons voyageurs qui côtoyaient voitures motorisées, téléphone et chars (p. 580-581) ou encore la culture de masse surannée (p. 601). Les avancées technologiques du XIXe siècle qui accrurent l'interdépendance et la communication entre les pays européens et entre les continents favorisèrent grandement l'étendue et l'intensité de la guerre. C'est là le paradoxe que souligne J. Leonhard et qu'il qualifie "d'ironie de la guerre» (Ironie des Krieges, p. 250). Pour analyser le fossé croissant entre les représentations des contemporains et la réalité en 
perpétuel changement, il a recours aux catégories d'attente et d'expérience forgées par Reinhart Kosellek. À la lumière de ces notions, il revient par exemple sur l'écart entre les représentations traditionnelles des dirigeants militaires et la puissance de feu des nouvelles armes (ex. p. 150). Ce fossé entre attentes et expériences ne cessa de se creuser au cours du conflit pour atteindre son apogée en 1916. En insistant sur le tournant que représenta cette année, présentée comme l'« anacrouse d'un changement de forme de la guerre » (Auftakt zu einem Formwandel des Krieges, p. 609) tant aux plans stratégico-militaire (grignotage plutôt que percée) qu'économique et sociétal (mobilisation accrue, voire "totale ", des sociétés, perte de légitimité et de sens de la guerre aux yeux des populations), J. Leonhard nuance l'idée d'une continuité sur la longue durée et, de ce fait, d'une guerre de Trente Ans entre 1914 et 1945 (p. 613).

Par ailleurs, en soulignant l'interdépendance politique, économique et commerciale qui s'était tissée entre les continents avant 1914 grâce aux infrastructures et aux réseaux de communication, l'auteur met en avant la dimension globale de la guerre. Il se penche sur les théâtres d'opération extra-européens, en Asie et en Afrique, sans délaisser les enjeux de la guerre navale et sous-marine. Selon lui, la Première Guerre mondiale bouleversa les rapports entre l'Europe et le reste du monde en inaugurant une nouvelle phase de la colonisation et de la décolonisation. Dès 1914 les colonies, impliquées dans le conflit, ne furent pas un simple " prolongement géographique de la guerre menée en Europe" (verlängerter Kriegsraum Europas, p. 194). Elles se caractérisaient au contraire par leur dynamique propre, échappant aux plans stratégiques des belligérants européens. De ce point de vue, l'histoire globale du conflit n'est pas seulement écrite a posteriori par l'historien: les contemporains aussi perçurent ce phénomène. Le Reich allemand, qui avait espéré que les empires coloniaux resteraient tenus à l'écart du conflit, perdit bientôt ses colonies, à l'exception de l'Afrique orientale allemande. J. Leonhard souligne que la guerre dans cette colonie est " un chapitre presque oublié " (ein fast vergessenes Kapitel, p. 204) de l'histoire de la Première Guerre mondiale. Comme dans la plupart des colonies, le nombre de victimes y est largement sous-estimé : si l'on prend en compte les porteurs indigènes recrutés de force et les victimes civiles le bilan pour cette seule colonie s'élève à près de 650000 morts, soit le taux de mortalité de civils le plus élevé après celui de la grippe espagnole par rapport à la population totale du pays. Par ailleurs, les territoires d'outre-mer représentaient un enjeu économique conséquent pour les puissances européennes dans la mesure où leurs habitants constituaient une ressource en main d'œuvre. Entre août 1916 et la fin du conflit 140000 ouvriers chinois furent recrutés dans les industries de guerre française et britannique (p. 561).

Après son analyse détaillée des causes et du déroulement du conflit, J. Leonhard se penche enfin sur la période de passage de la guerre à la paix. Il constate là une «fin asynchrone de la guerre et de la paix » (Ungleichzeitigkeit von Krieg und Frieden, p. 926) et accorde une attention particulière aux conflits qui éclatèrent après 1918-1919, en Russie, en Pologne, dans les pays baltes ou encore en Turquie. La boîte de Pandore était bel et bien ouverte...

Vous trouverez la table des matières ici : http://d-nb.info/1043656944/04. 
INDEX

Index chronologique : Époque contemporaine

Thèmes : Histoire économique, Histoire militaire, Histoire sociale

\section{AUTEUR}

BÉRÉNICE ZUNINO

Institut français d'histoire en Allemagne, Francfort-sur-le-Main 